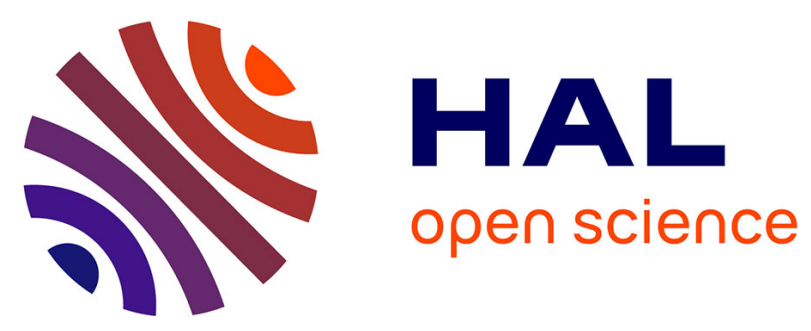

\title{
Dy 3+ White Light Emission Can Be Finely Controlled by Tuning the First Coordination Sphere of Ga 3+/Dy 3+ Metallacrown Complexes
}

Svetlana Eliseeva, Elvin Salerno, Beatriz Lopez Bermudez, Stephane Petoud, Vincent Pecoraro

\section{To cite this version:}

Svetlana Eliseeva, Elvin Salerno, Beatriz Lopez Bermudez, Stephane Petoud, Vincent Pecoraro. Dy $3+$ White Light Emission Can Be Finely Controlled by Tuning the First Coordination Sphere of Ga 3+ /Dy 3+ Metallacrown Complexes. Journal of the American Chemical Society, 2020, 142 (38), pp.16173-16176. 10.1021/jacs.0c07198 . hal-02975958

\section{HAL Id: hal-02975958 https://hal.science/hal-02975958}

Submitted on 16 Nov 2020

HAL is a multi-disciplinary open access archive for the deposit and dissemination of scientific research documents, whether they are published or not. The documents may come from teaching and research institutions in France or abroad, or from public or private research centers.
L'archive ouverte pluridisciplinaire HAL, est destinée au dépôt et à la diffusion de documents scientifiques de niveau recherche, publiés ou non, émanant des établissements d'enseignement et de recherche français ou étrangers, des laboratoires publics ou privés. 


\title{
$D^{3+}$ white light emission can be finely controlled by tuning the first coordination sphere of $\mathrm{Ga}^{3+} / \mathrm{Dy}^{3+}$ metallacrown complexes
}

\author{
Svetlana V. Eliseeva,,,+ Elvin V. Salerno, ${ }^{\ddagger}$ Beatriz A. Lopez Bermudez, Stéphane Petoud, ${ }^{*}$ and Vin- \\ cent L. Pecoraro*
}

\begin{abstract}
Single lanthanide(III) ion white light emission is in high demand since it provides the advantage of requiring only one chromophore for the control of the color. Herein, a series of $\mathrm{Ga}^{3+} / \mathrm{Dy}^{3+}$ metallacrowns (MCs) is presented, demonstrating outstanding white light colorimetric properties with CIE chromaticity coordinates of $(0.309,0.334)$ and correlated color temperature (CCT) equal to $6670 \mathrm{~K}$ for the $\mathrm{MC}$ emitting the closest to the standard white color. Experimental data reveal that the CIE coordinates within the studied series of MCs are controlled mainly by the Dy ${ }^{3+}$-centered emission rather than by the ligand-centered bands, implying that $\mathrm{Dy}^{3+}$ can be tuned as a single ionic white light emitter by a simple modification of the coordination environment.
\end{abstract}

Controlled light is extremely important in the modern technological age. Systems which last longer, are brighter, and use less power are necessary to keep up with the increasing energy demand and to reduce environmental strain. White light emission (WLE) has a key role to play in general lighting, displays, and communications (e.g. emerging "LiFi" technology). ${ }^{1}$ For general lighting, pure white light is desirable such that our color perception is true. Indeed, the quality and constancy of white light is essential for a broad range of applications, a typical example being surgical settings where it is critical that physicians can unambiguously perceive proper colors within their working environment. ${ }^{2}$ Bright, constant and calibrated WLE is also of major importance for screen backlighting in LCD or LED displays. ${ }^{3}$ These types of flat displays function by modulating the component colors of the white light which pass through their filters. ${ }^{4}$ In CIE (Commission Internationale d'Eclairage) 1931 color coordinates, which are used to quantify a standardized human perception of color, $(x, y)$ coordinates of $(0.33,0.33)$ are considered as providing an optimal white light emission. ${ }^{5}$

One way to categorize strategies of production of white light is based on the number of emitting center types. Thus, dichroic, trichroic and tetrachroic strategies can be distinguished that use a combination of blue/yellow, red/green/blue (RGB) and RGB/cyano emitters, respectively. ${ }^{6}$ Oftentimes, different co-doped lanthanide(III) ions $\left(\mathrm{Ln}^{3+}\right)$ can produce these colored emissions. $\mathrm{Ln}^{3+}$ emission can also be combined with blue organic emissions. ${ }^{7,8} \mathrm{Ln}^{3+}$ are attractive for this application as they emit "pure colors" as sharp emission bands, the wavelengths of which are not highly affected by changes in the experimental conditions (such as the temperature, for example). Alternatively, multiple materials with individual colorimetric characteristics can be combined in an appropriate ratio. ${ }^{1}$ Single-compound emitters are highly desirable since they have the potential to be the main component for a simpler production of lighter and thinner materials. ${ }^{9}$ This approach has been used, for example, with the 1,8-naphthalimide/Eu ${ }^{3+}$ complex, in which green and blue emissions from the chromophoric ligand have been coupled with $\mathrm{Eu}^{3+}$ red emission to form observed white light; ${ }^{10}$ or in a binuclear $\mathrm{Dy}^{3+}$ complex where blue ligand emission has been combined with complementary Dy ${ }^{3+}$ yellow emission. ${ }^{11}$

The design of such complexes is often difficult since it is unlikely that one chromic component can be altered without affecting the others in an unpredictable manner. A different approach is based on the emission from a single ion as the resulting global emission is more easily tunable along one experimental coordinate. WLE derived from $\mathrm{Dy}^{3+}$ has been demonstrated in solid state glasses. For example, Kaewkhao et.al. have found that WLE characteristics were different for bismuth borate and zinc bismuth borate glasses doped with similar concentrations of $\mathrm{Dy}^{3+} \cdot .^{12}$ Other studies involving Dy ${ }^{3+}$-doped barium silicate ${ }^{13}$ and lithium zinc borosilicate ${ }^{14}$ glasses have demonstrated that CIE coordinates could be tuned by the choice of $\mathrm{Dy}^{3+}$ doping concentration.

Herein, we present a series of single-molecular white light emitting $\mathrm{Ga}^{3+} / \mathrm{Dy}^{3+}$ metallacrowns (MCs) with optical excitation at $340 \mathrm{~nm}$. We simultaneously present evidence that WLE characteristics of single $\mathrm{Dy}^{3+}$ ions can be modulated by altering the crystal field (CF) about them.

Each of the presented MCs shares a common 12-metallacrown-4 motif based on diamagnetic $\mathrm{Ga}^{3+}$ ring metals and salicylhydroxamic acid $\left(\mathrm{H}_{3}\right.$ shi) ring ligands, $\left[12-\mathrm{MC}_{\mathrm{Ga}}{ }^{\mathrm{III}} \mathrm{N}\left(\right.\right.$ shi) ${ }^{-}$ 4]; ${ }^{15,16}$ however, the geometry about the $\mathrm{Dy}^{3+}$, as well as the counter cations balancing charges in the structures are varied. Four MCs that we have previously described are newly analyzed for WLE: $\left[\mathrm{DyGa}_{4}\left(\mathrm{shi}_{4}(\mathrm{bz})_{4}\right](\mathrm{pyH}) \quad(\mathbf{1}),{ }^{17}\right.$ $\left[\mathrm{DyGa}_{4}(\mathrm{shi})_{4}\left(\mathrm{H}_{2} \mathrm{Shi}_{2}\left(\mathrm{NO}_{3}\right)\right](2){ }_{18}^{18}\left[\mathrm{Dy}_{2} \mathrm{Ga}_{8}(\mathrm{shi})_{8}(\mathrm{ip})_{4}\right]\left(\mathrm{NH}_{4}\right)_{2}\right.$ (3), ${ }^{19}\left[\mathrm{DyGa}_{8}(\mathrm{shi})_{8}(\mathrm{OH})_{4}\right] \mathrm{Na}(4)^{20}\left(\mathrm{bz}^{-}=\right.$benzoate, $\mathrm{pyH}^{+}=$ pyridinium, $\mathrm{ip}^{2-}=$ isophthalate). In addition, the novel MC, $\left[\mathrm{DyGa}_{4}(\mathrm{shi})_{4}(\mathrm{bz})_{4}\right] \mathrm{Na}(\mathbf{5})$, has been synthesized and fully characterized (Figure 1, Scheme S1). $\mathbf{5}$ is an identical MC to $\mathbf{1}$, with the difference of containing a sodium counter cation rather than a pyridinium cation. This substitution was made to evaluate if the reduction of the number of $\mathrm{C}-\mathrm{H}$ and $\mathrm{N}-\mathrm{H}$ 
oscillators in the solid state could increase the Dy ${ }^{3+}$-centered quantum yield $\left(Q_{\mathrm{Dy}}^{\mathrm{L}}\right)$ of the $\mathrm{Ga}^{3+} / \mathrm{Dy}^{3+} \mathrm{MC}$ since X-H oscillators are known to non-radiatively deactivate the excited states of $\mathrm{Ln}^{3+} .21$
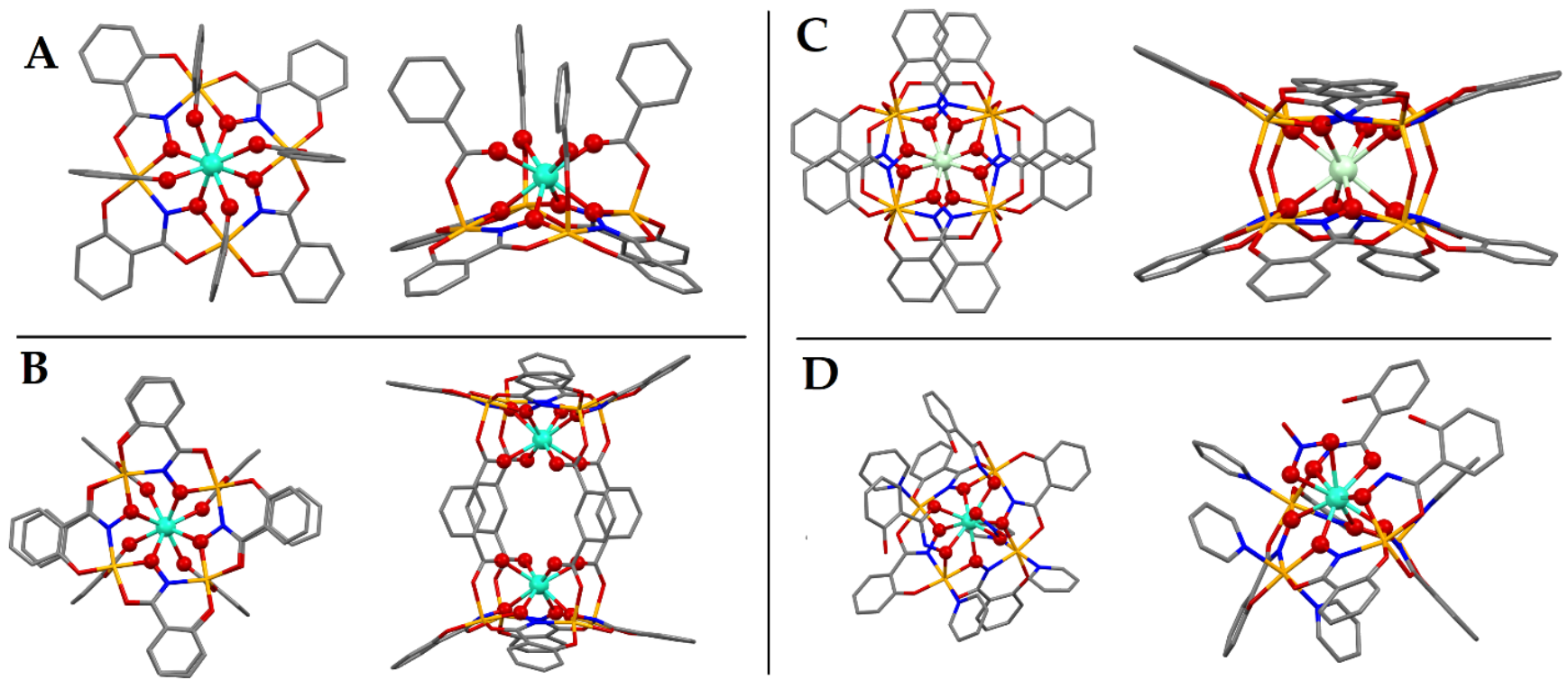

Figure 1. Multiple views of the $\mathrm{Ga}^{3+} / \mathrm{Dy}^{3+} \mathrm{MCs}$ geometries. (A) [DyGa4(shi)4(bz) 4 corresponding to $\mathbf{1}$ and $\mathbf{5}$. The crystal structure was solved for [DyGa4(shi) $4(\mathrm{bz})_{4}(\mathrm{pyH})(\mathbf{1}),{ }^{17}$ however mass spectrometry and elemental analysis reveal identical molecular composition (Supporting Information). (B) [Dy2 $\mathrm{Ga}_{8}(\mathrm{shi})_{8}(\mathrm{ip})_{4}\left(\mathrm{NH}_{4}\right)_{2}(3) .{ }^{19}$ (C) [DyGa8 $\left.(\mathrm{shi})_{8}(\mathrm{OH})_{4}\right]_{\mathrm{Na}}(\mathbf{4})$. $^{20}$ The structure was solved for isostructural $\left[\mathrm{NdGa}_{8}(\mathrm{shi})_{8}(\mathrm{OH})_{4}\right] \mathrm{Na}$. (D) $\left[\mathrm{DyGa}_{4}(\mathrm{shi})_{4}\left(\mathrm{H}_{2} \mathrm{Shi}\right)_{2}\left(\mathrm{NO}_{3}\right)\right]$ (2). ${ }^{18}$ The structure was solved for isostructural $\left[\mathrm{TbGa}_{4}(\mathrm{shi})_{4}\left(\mathrm{H}_{2} \mathrm{Shi}\right)_{2}\left(\mathrm{NO}_{3}\right)\right]$, four coordinating pyridines are shown here. Solvents of crystallization, non-integral counter ions, and hydrogen atoms are omitted. Central $\mathrm{Ln}^{3+}$ and coordinating oxygen atoms are bolded for highlight effect. Color code: Ga-orange; Naviolet; Ln-teal; O-red; N-blue; C-grey.

Excitation spectra of $\mathrm{Ga}^{3+} / \mathrm{Dy}^{3+}$ MCs upon monitoring the ${ }^{4} \mathrm{~F}_{9 / 2} \rightarrow{ }^{6} \mathrm{H}_{13 / 2}$ transition appearing at $575-577 \mathrm{~nm}$ are dominated by the broad bands in the UV up to $400 \mathrm{~nm}$ with sharp features of lower intensity that correspond to the Dy ${ }^{3+} \mathrm{f}-\mathrm{f}$ transitions (Figure S2). Such behavior confirms an efficient sensitization of $\mathrm{Dy}^{3+}$ emission through the MC scaffold. Within the studied series of $\mathrm{Ga}^{3+} / \mathrm{Dy}^{3+} \mathrm{MCs}$, the energy positions of the ligand triplet states $\left(\mathrm{T}_{1}\right.$ ) are similar (Table S2). This observation can be explained by the major role of the [12- $\left.\mathrm{MC}_{\mathrm{Ga}}{ }^{\mathrm{III}} \mathrm{N}(\mathrm{shi})-4\right]$ moieties in the sensitization of $\mathrm{Dy}^{3+}$ emission in all MCs, rather than the other residues found in the complexes, i.e. $\mathrm{bz}^{-}, \mathrm{ip}^{2-}, \mathrm{pyH}^{+}$, and $\mathrm{OH}^{-}$. The nature of the latter, however, are highly relevant to changes of the $\mathrm{CF}$ about the $\mathrm{Dy}^{3+}$.

To analyze WLE properties, $\mathrm{Ga}^{3+} / \mathrm{Dy}^{3+} \mathrm{MCs}$ were optically excited at $340 \mathrm{~nm}$ and emission spectra were recorded in the range of 360-700 nm (Figure 2) and used for the calculation of the corresponding CIE coordinates and CCT (Correlated Color Temperature) values (Figure 3, Tables 1 and S4). CCT defines the color appearance of a white light. Warm light is around $2700 \mathrm{~K}$, neutral white is around $4000 \mathrm{~K}$, and cool white is $>5000 \mathrm{~K}$. Emission spectra of $\mathrm{Ga}^{3+} / \mathrm{Dy}^{3+}$ MCs have a generally similar emission profile: (i) a weak and broad band in the range of 360-445 $\mathrm{nm}$ corresponding to $\pi-\pi^{*}$ transitions within the organic ligands, and (ii) three sharp bands in the range of 445-700 $\mathrm{nm}$ that are assigned to $\mathrm{Dy}^{3+}{ }^{4} \mathrm{~F}_{9 / 2} \rightarrow^{6} \mathrm{H}_{J}(J=15 / 2,13 / 2,11 / 2)$ transitions. However, the relative intensities of these emission bands (Table S3) as well crystal-field splitting of the f-f transitions vary depending on the composition of the MC. The latter also affects quantitative characteristics of 1-5, namely ligand-centered $\left(Q_{\mathrm{L}}^{\mathrm{L}}\right)$ and $Q_{\mathrm{Dy}}^{\mathrm{L}}$ quantum yields (Table 1 ) as well as Dy ${ }^{3+}$ luminescence lifetimes ( $\tau_{\mathrm{obs}}$, Table S5). Is should be noted that despite the similarity of the $\mathrm{T}_{1}$ energies of the ligands within the series of $\mathrm{Ga}^{3+} / \mathrm{Dy}^{3+} \mathrm{MCs}, Q_{\mathrm{Dy}}^{\mathrm{L}}$ and $\tau_{\text {obs }}$ vary significantly- from $0.222(6)$ to $8.3(3) \%$ and $3.36(6)$ to $50.9(6) \mu \mathrm{s}$, respectively. An important consideration is the role of the counter-cation already mentioned by us for $\left[\mathrm{Yb}_{2} \mathrm{Ga}_{8}(\mathrm{shi})_{8}(\mathrm{ip})_{4}\right]$ dimers. ${ }^{22}$ Indeed, the $\tau_{\text {obs }}$ is 2.4 times longer for 5 compared to $1(50.9(6) v s .21 .2(2) \mu s)$, while $Q_{\text {Dy }}^{\mathrm{L}}$ is enhanced 6.3-times reaching 8.3(3)\% for the former MC.

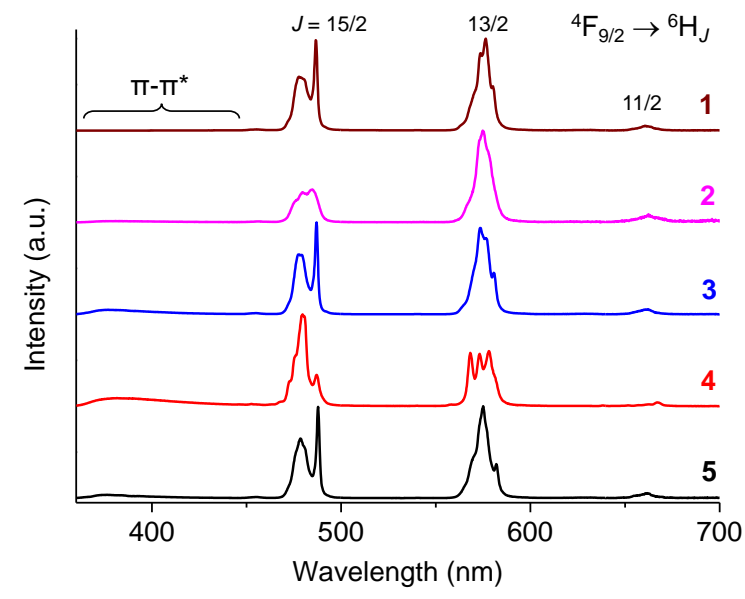

Figure 2. Corrected and normalized emission spectra of $\mathrm{Ga}^{3+} / \mathrm{Dy}^{3+}$ MCs in the solid state under excitation at $340 \mathrm{~nm}$, room temp. 
Considering the resulting CIE diagram, three main groups could be distinguished as corresponding to the three general molecular geometries (Table S1, Figures 1 and S1). Compounds $\mathbf{1}, \mathbf{3}$, and $\mathbf{5}$ have all similar 8 -coordinate pseudo- $C_{4}$ symmetry. Indeed, $\mathbf{1}$ and $\mathbf{5}$ are identical molecular units with disparate counter cations, while $\mathbf{3}$ is the structural dimer of $\mathbf{1}$ and $\mathbf{5}$ where the $\mathrm{bz}^{-}$ligands bridging $\mathrm{Dy}^{3+}$ to the $\left[12-\mathrm{MC}_{\mathrm{Ga}}{ }^{\mathrm{III}} \mathrm{N}(\mathrm{shi})-4\right]$ core have been replaced with ip ${ }^{2-}$ to link the two DyGa ${ }_{4}$ monomers. These structures possess four oxygen atoms derived from the shi ${ }^{3-}$ ligands, and four oxygen atoms derived from the aromatic carboxylates, either bz $(\mathbf{1}, \mathbf{5})$ or $\mathrm{ip}^{2-}(\mathbf{3})$. MC $\mathbf{2}$ is a less symmetrical 9coordinate complex with a symmetry more akin to a simple $C_{1}$. It has four oxygen atoms derived from the $\mathrm{shi}^{3-}$, as well as two oxygen atoms from the nitrate anion bound in a $\mu_{2}-\mathrm{NO}_{3}-$ pattern, and finally, three oxygen atoms from the $\mathrm{H}_{2}$ shi- bridging ligands. 4 is the most symmetrical MC within the series exhibiting pseudo- $S_{8}$ symmetry with eight oxygen atoms from the $\mathrm{shi}^{3-} \mathrm{co}^{-}$ ordinating in an approximately square antiprismatic geometry. Because all coordinating atoms in $\mathbf{4}$ are coming from the MC core, the two [12- $\left.\mathrm{MC}_{\mathrm{Ga}}{ }^{\mathrm{III}} \mathrm{N}(\mathrm{shi})-4\right]$ planes are essentially equidistant from $\mathrm{Dy}^{3+}$ in this molecule. It should be noted that MCs 1, 3, 4 and 5 have essentially a planar [12-MCGa $\left.{ }^{\mathrm{III}} \mathrm{N}(\mathrm{shi})-4\right]$ core, while 2 possesses a highly distorted MC ring.

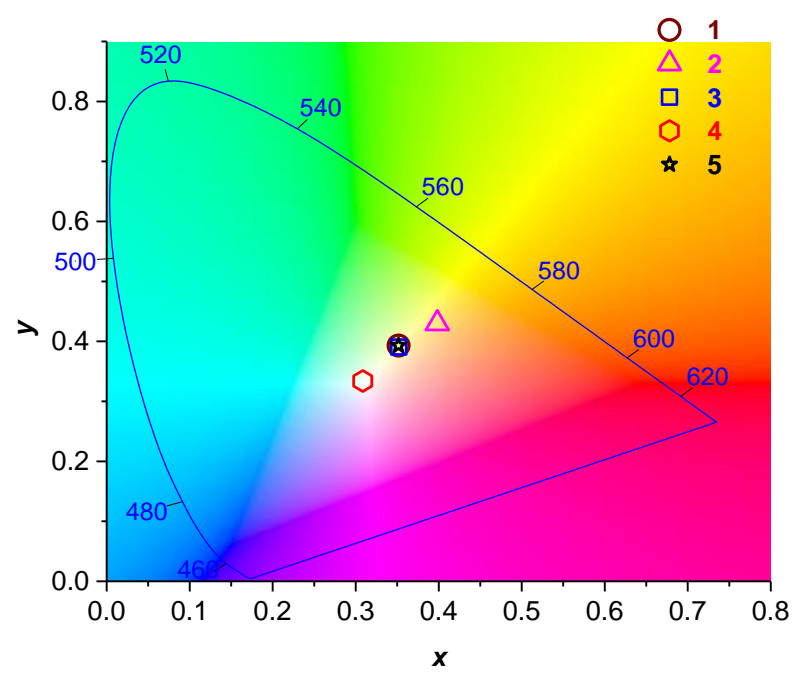

Figure 3. CIE 1931 chromaticity coordinate diagram for 1-5.

Table 1. Quantum yields and CIE 1931 coordinates $(x, y)$ for $\mathrm{Ga}^{3+} / \mathrm{Dy}^{3+} \mathrm{MCs}$ in the solid state.

\begin{tabular}{lllllll}
\hline $\mathrm{MC}$ & $x^{b}$ & $y^{b}$ & $\begin{array}{l}\mathrm{CCT} \\
(\mathrm{K})^{c}\end{array}$ & $Q_{\mathrm{Dy}}^{\mathrm{L}}(\%)^{d}$ & $Q_{\mathrm{L}}^{\mathrm{L}}(\%)^{e}$ & $\frac{Q_{\mathrm{L}}^{\mathrm{L}}}{Q_{\text {Total }}^{\mathrm{L}}}$ \\
\hline $\mathbf{1}$ & 0.352 & 0.393 & 4888 & $1.23(2)$ & $0.0043(1)$ & 0.0035 \\
$\mathbf{2}$ & 0.398 & 0.430 & 3917 & $0.222(6)$ & $0.0091(1)$ & 0.039 \\
$\mathbf{3}$ & 0.352 & 0.391 & 4882 & $0.85(1)$ & $0.086(1)$ & 0.092 \\
$\mathbf{4}$ & 0.309 & 0.334 & 6670 & $1.42(8)$ & $0.34(1)$ & 0.193 \\
$\mathbf{5}$ & 0.352 & 0.393 & 4888 & $8.3(3)$ & $0.54(2)$ & 0.060 \\
\hline
\end{tabular}

${ }^{a}$ At room temperature upon 330-350 nm excitation; $2 \sigma$ values between parentheses; experimental errors: $Q, \pm 10 \%$. ${ }^{b}$ Calculated for the 380-700 $\mathrm{nm}$ range. ${ }^{c}$ Estimated from CIE coordinates using eq. $(\mathrm{S} 1 \mathrm{a}, \mathrm{b}) .{ }^{d}$ The quantum yield of the $\mathrm{Dy}^{3+}$-centered emission. ${ }^{e}$ The quantum yield of the ligand-centered emission.
The nature of the ligands is not only important in controlling the luminescence properties of the $\mathrm{Dy}^{3+}$-centered emission, the ligand-centered emission may also contribute to the overall luminescence profile (Figure 2) of the MC and, in turn, affect CIE coordinates. Analysis of the corresponding quantum yields allowed to estimate the magnitude of the ligands contribution to the total emission (Table 1). This parameter varies from $0.35 \%$ for $\mathbf{1}$ to $19.3 \%$ for $\mathbf{4}$. For the $C_{4}$-type MCs (1, $\mathbf{3}$ and $\left.\mathbf{5}\right)$, the similar CIE coordinates and CCT values were found regardless the contribution of the ligands emission and the quantum yield values. The nature of the counter-cation (essential for $Q_{\mathrm{Dy}}^{\mathrm{L}}$ and $\tau_{\mathrm{obs}}$ ) has a minimal effect on the color characteristics (1 vs. 5). On the other hand, 2 emits a much warmer light than 4 (Figure 3). Nevertheless, the contribution of the ligand emission to CIE coordinates of $\mathrm{Ga}^{3+} / \mathrm{Dy}^{3+} \mathrm{MCs}$ can be considered as being minimal compared to the impact of the CF induced by the coordination environment about $\mathrm{Dy}^{3+}$ (Table S4, Figure S3).

Taking the latter point into account, it appears that Dy ${ }^{3+}$ WLE can be tuned solely on the basis of the CF that is able to change the Stark splitting and the intensity of each of the Dy ${ }^{3+}$ electronic transitions. ${ }^{23-25}$ The $\mathrm{Dy}^{3+}$ emission signals in the visible region arise from the ${ }^{4} \mathrm{~F}_{9 / 2}$ emitting state (Figure 2). Since human perception of white light is dependent on the additive contributions from multiple visible colors, the wavelength and relative intensities of these transitions are highly important. The contributing transitions in the visible region for $\mathrm{Dy}^{3+}$ are ${ }^{4} \mathrm{~F}_{9 / 2} \rightarrow{ }^{6} \mathrm{H}_{15 / 2}(480$ $\mathrm{nm}$, blue), ${ }^{4} \mathrm{~F}_{9 / 2} \rightarrow{ }^{6} \mathrm{H}_{13 / 2}$ (575 nm, golden-yellow), and minimally ${ }^{4} \mathrm{~F}_{9 / 2} \rightarrow{ }^{6} \mathrm{H}_{11 / 2}(665 \mathrm{~nm}$, red). The human colorimetric perception of the corresponding wavelengths was assigned based on Helmholtz's color assessment. ${ }^{26}$ By this scheme, the Dy ${ }^{3+}$ ion is a trichroic white light producer possessing particular relative integrated intensities of each blue, golden-yellow, and red contributions (Table S3). As a consequence, CIE coordinates can be tuned by the CF. Indeed, 1, 3 and $\mathbf{5}$ with pseudo- $C_{4}$ symmetry exhibit emission bands with similar Stark splitting and relative integrated intensities for blue (39-44\%), golden-yellow (48-52\%) and red (3.6-4.0\%) contributions. The emission spectrum of the less symmetrical 2 is dominated by the ${ }^{4} \mathrm{~F}_{9 / 2} \rightarrow{ }^{6} \mathrm{H}_{13 / 2}$ transition $(60 \%)$ while blue and red components contribute at levels of 28 and $8.2 \%$, respectively, moving its CIE coordinates and CCT to the warm white region. Finally, 4 displays the closest CIE coordinates to standard white light and exhibits an emission spectrum with similar contributions from blue and golden-yellow components ( 42 and $36 \%$ ), in addition to the $2 \%$ red contribution.

In summary, a series of five $\mathrm{Ga}^{3+} / \mathrm{Dy}^{3+} \mathrm{MCs}$ were analyzed for their WLE properties, with the novel $\left[\mathrm{DyGa}_{4}(\mathrm{shi})_{4}(\mathrm{bz})_{4}\right] \mathrm{Na}(\mathbf{5})$ demonstrating the ability to drastically increase the $Q_{\mathrm{Dy}}^{\mathrm{L}}$ by the judicious selection of the molecular counter cation. Moreover, CIE coordinates of $\left[\mathrm{DyGa}_{8}(\mathrm{shi})_{8}(\mathrm{OH})_{4}\right] \mathrm{Na}(4)(0.309,0.334)$ are close to the ideal white light with CCT in the cold white region. Importantly, the present study represents a promising approach for the tuning of single Dy ${ }^{3+}$ WLE based on CF considerations and is likely to be transferrable across different $\mathrm{Dy}^{3+}$ host compounds.

\section{ASSOCIATED CONTENT}

Experimental details and additional information about analysis of crystal structures and photophysical data. This material is available free of charge via the Internet at http://pubs.acs.org." 


\section{AUTHOR INFORMATION}

\section{*Corresponding Authors}

Svetlana V. Eliseeva - Centre de Biophysique Moléculaire, CNRS UPR 4301, F-45071 Orleans Cedex 2, France.

Email: svetlana.eliseeva@cnrs-orleans.fr

Stéphane Petoud - Centre de Biophysique Moléculaire, CNRS UPR 4301, F-45071 Orleans Cedex 2, France.

Email: stephane.petoud@inserm.fr

Vincent L. Pecoraro - Department of Chemistry, Willard H. Dow Laboratories, University of Michigan, Ann Arbor, Michigan 48109, USA; Email:vlpec@umich.edu

\section{Authors}

Elvin V. Salerno - Department of Chemistry, Willard H. Dow Laboratories, University of Michigan, Ann Arbor, Michigan 48109, USA.

Beatriz A. Lopez Bermudez - Department of Chemistry, Willard H. Dow Laboratories, University of Michigan, Ann Arbor, Michigan 48109, USA.

\section{Author Contributions}

The manuscript was written through contributions of all authors. All authors have given approval to the final version of the manuscript. tThese authors contributed equally.

\section{ACKNOWLEDGMENTS}

The work was supported through grants from the National Science Foundation (CHE 1664964 for VLP and EVS, DGE-1256260 for EVS), La Ligue Contre le Cancer and La Région Centre Val de Loire. SP thanks Institut National de la Santé et de la Recherche Médicale.

\section{ABBREVIATIONS}

CCT, Correlated Color Temperature; CF, crystal field; CIE, Commission Internationale d'Eclairage; LCD, liquid crystal display; LED, light-emitting diode; MC, metallacrown; WLE, white light emission.

\section{REFERENCES}

(1) Cho, J.; Park, J. H.; Kim, J. K.; Schubert, E. F. White Light-Emitting Diodes: History, Progress, and Future. Laser Photonics Rev. 2017, 11 (2): 1600147. https://doi.org/10.1002/lpor.201600147.

(2) Knulst, A. J.; Stassen, L. P. S.; Grimbergen, C. A.; Dankelman, J. Choosing Surgical Lighting in the LED Era. Surg. Innov. 2009, 16 (4) e44048, 317-323. https://doi.org/10.1177/1553350609353766.

(3) Chen, H.-W.; Lee, J.-H.; Lin, B.-Y.; Chen, S.; Wu, S.-T. Liquid Crystal Display and Organic Light-Emitting Diode Display: Present Status and Future Perspectives. Light Sci. Appl. 2018, 7 (3), 17168-17168. https://doi.org/10.1038/lsa.2017.168.

(4) Elze, T.; Tanner, T. G. Temporal Properties of Liquid Crystal Displays: Implications for Vision Science Experiments. PLoS One 2012, 7 (9). https://doi.org/10.1371/journal.pone.0044048.

(5) Choudhury, A. K. R. Using Instruments to Quantify Colour. In Principles of Colour and Appearance Measurement; Woodhead Publishing, 2014; pp 270-317. https://doi.org/10.1533/9780857099242.270.

(6) SeethaLekshmi, S.; Ramya, A. R.; Reddy, M. L. P.; Varughese, S. Lanthanide Complex-Derived White-Light Emitting Solids: A Survey on Design Strategies. J. Photochem. Photobiol. C Photochem. Rev. 2017, 33, 109-131. https://doi.org/10.1016/j.jphotochemrev.2017.11.001.

(7) Yang, Q. Y.; Wu, K.; Jiang, J. J.; Hsu, C. W.; Pan, M.; Lehn, J. M.; Su, C. Y Pure White-Light and Yellow-to-Blue Emission Tuning in Single Crystals of Dy(III) Metal-Organic Frameworks. Chem. Commun. 2014, 50 (57), 7702-7704. https://doi.org/10.1039/c4cc01763c.

(8) Kotova, O.; Comby, S.; Lincheneau, C.; Gunnlaugsson, T. White-Light Emission from Discrete Heterometallic Lanthanide-Directed SelfAssembled Complexes in Solution. Chem. Sci. 2017, 8 (5), 3419-
3426. https://doi.org/10.1039/c7sc00739f.

Law, G. L.; Wong, K. L.; Tam, H. L.; Cheah, K. W.; Wong, W. T. White OLED with a Single-Component Europium Complex. Inorg. Chem. 2009, 48 (22), $10492-10494$. https://doi.org/10.1021/ic9018037.

(10) Shelton, A. H.; Sazanovich, I. V.; Weinstein, J. A.; Ward, M. D. Controllable Three-Component Luminescence from a 1,8Naphthalimide/Eu(III) Complex: White Light Emission from a Single Molecule. Chem. Commun. 2012, 48 (22), 2749-2751. https://doi.org/10.1039/c2cc17182a.

(11) Manzur, J.; De Santana, R. C.; Maia, L. J. Q.; Vega, A.; Spodine, E Tuning White Light Emission in Dinuclear Phenoxo Bridged Dy ${ }^{\mathrm{III}}$ Complexes. Inorg. Chem. 2019, 58 (15), 10012-10018. https://doi.org/10.1021/acs.inorgchem.9b01153.

(12) Yasaka, P.; Boonin, K.; Kaewkhao, J. White Light Emission from Dy ${ }^{3+}$ Doped Zinc Bismuth Borate and Bismuth Borate Glasses: A Comparative Study. Key Eng. Mater. 2016, 675-676, 409-413. https://doi.org/10.4028/www.scientific.net/KEM.675-676.409. Mishra, L.; Sharma, A.; Vishwakarma, A. K.; Jha, K.; Jayasimhadri, M.; Ratnam, B. V.; Jang, K.; Rao, A. S.; Sinha, R. K. White Light Emission and Color Tunability of Dysprosium Doped Barium Silicate Glasses. J. Lumin. 2016, 169, 121-127. https://doi.org/10.1016/j.jlumin.2015.08.063.

Jaidass, N.; Krishna Moorthi, C.; Mohan Babu, A.; Reddi Babu, M. Luminescence Properties of $\mathrm{Dy}^{3+}$ Doped Lithium Zinc Borosilicate Glasses for Photonic Applications. Heliyon 2018, 4 (3), e00555. https://doi.org/10.1016/j.heliyon.2018.e00555.

(15) Lutter, J. C.; Zaleski, C. M.; Pecoraro, V. L. Chapter Four Metallacrowns: Supramolecular Constructs With Potential in Extended Solids, Solution-State Dynamics, Molecular Magnetism, and Imaging. In Advances in Inorganic Chemistry; van Eldik, R., Puchta, R. B. T.-A. in I. C., Eds.; Academic Press, 2018; Vol. 71, pp 177-246.

https://doi.org/https://doi.org/10.1016/bs.adioch.2017.11.007.

(16) Mezei, G.; Zaleski, C. M.; Pecoraro, V. L. Structural and Functional Evolutions of Metallacrowns. Chem. Rev. 2007, 107 (11), 49335003. https://doi.org/10.1021/cr078200h.

(17) Chow, C. Y.; Eliseeva, S. V.; Trivedi, E. R.; Nguyen, T. N.; Kampf, J. W.; Petoud, S.; Pecoraro, V. L. Ga ${ }^{3+} / \mathrm{Ln}^{3+}$ Metallacrowns: A Promising Family of Highly Luminescent Lanthanide Complexes That Covers Visible and Near-Infrared Domains. J. Am. Chem. Soc. 2016, 138 (15), 5100-5109. https://doi.org/10.1021/jacs.6b00984.

(18) Nguyen, T. N.; Eliseeva, S. V.; Chow, C. Y.; Kampf, J. W.; Petoud, S.; Pecoraro, V. L. Peculiarities of Crystal Structures and Photophysical Properties of $\mathrm{Ga}^{3+} / \mathrm{Ln}^{3+}$ Metallacrowns with a Non-Planar [12-MC4] Core. Inorg. Chem. Front. 2020, 7, 1553-1563. https://doi.org/10.1039/c9qi01647c.

(19) Nguyen, T. N.; Chow, C. Y.; Eliseeva, S. V.; Trivedi, E. R.; Kampf, J. W.; Martinić, I.; Petoud, S.; Pecoraro, V. L. One-Step Assembly of Visible and Near-Infrared Emitting Metallacrown Dimers Using a Bifunctional Linker. Chem. - A Eur. J. 2018, 24 (5), 1031-1035. https://doi.org/10.1002/chem.201703911.

(20) Salerno, E. V.; Eliseeva, S. V.; Schneider, B. L.; Kampf, J. W.; Petoud S.; Pecoraro, V. L. Visible, near-Infrared, and Dual-Range Luminescence Spanning the $4 \mathrm{f}$ Series Sensitized by Dimeric Gallium(III)/Lanthanide(III) Metallacrown. Submitted.

(21) Bünzli, J.-C.; Eliseeva, S. V. Basics of Lanthanide Photophysics. In Lanthanide Luminescence: Photophysical, Analytical and Biological Aspects; Springer-Verlag Berlin Heidelberg, 2011; pp 1-46. https://doi.org/10.1007/978-3-642-21023-5.

(22) Lutter, J. C.; Eliseeva, S. V; Collet, G.; Martinic, I.; Kampf, J. W.; Schneider, B. L.; Carichner, A.; Sobilo, J.; Lerondel, S.; Petoud, S. Pecoraro, V. L. Iodinated Metallacrowns: Toward Combined Bimodal Near-Infrared and X-ray Contrast Imaging Agents. Chem. A Eur. J. 2019, 26, 1274-1277. https://doi.org/10.1002/chem.201905241.

(23) Walsh, B. M. Judd-Ofelt Theory: Principles and Practices. In Advances in Spectroscopy for Lasers and Sensing; Springer, Dordrecht, 2006; pp 403-433. https://doi.org/https://doi.org/10.1007/1-4020-4789-4_21.

(24) Schweizer, T.; Hewak, D. W.; Samson, B. N.; Payne, D. N. Spectroscopic Data of the 1.8-, 2.9-, and 4.3- UM Transitions in Dysprosium-Doped Gallium Lanthanum Sulfide Glass. Opt. Lett. 1996, 21 (19), 1594-1596. 
(25) Sastri, V. S.; Bünzli, J.-C.; Rao, V. R.; Rayudu, G. V. S.; Perumareddi, J. R. Spectroscopy of Lanthanide Complexes. In Modern Aspects of Rare Earths and Their Complexes; 2003; pp 569-731. https://doi.org/10.1016/b978-044451010-5/50022-5.

(26)

Choudhury, A. K. R. Principles of Colour Perception. In Principles of
Colour and Appearance Measurement; Woodhead Publishing, 2014; pp 144-184. https://doi.org/10.1533/9780857099242.144. 
TOC artwork

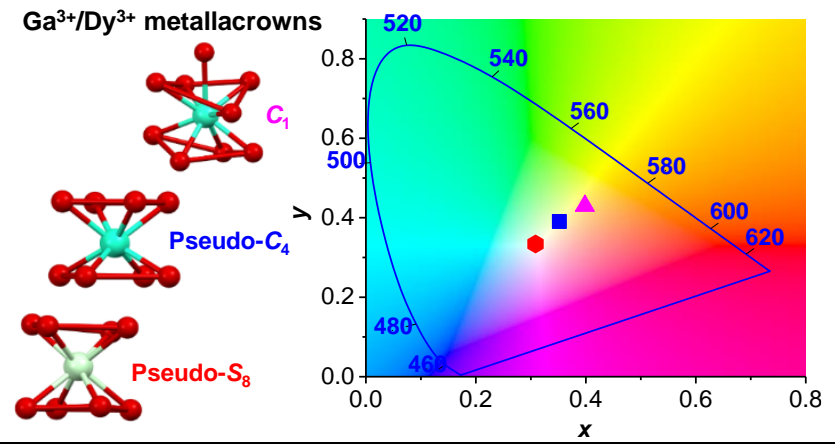

